\title{
EQUIPMENT CONDITION FOR ZEBRA CROSSING NIGHT-TIME SAFETY PERFORMANCE IN LATVIA
}

\author{
MARIS SEFLERS ${ }^{1,2^{*}}$, JURIS KREICBERGS ${ }^{1}$, \\ GERNOT SAUTER ${ }^{3}$ \\ ${ }^{1}$ Department of Automotive Engineering, Riga Technical University, \\ Riga, Latvia \\ ${ }^{2}$ Transportation Safety Division, 3M Latvia, Riga, Latvia \\ ${ }^{3}$ Transportation Safety Division Laboratory, 3M Germany, Neuss, Germany
}

Received 31 May 2021; accepted 5 December 2021

\begin{abstract}
According to road traffic accident (hereinafter referred to as RTA) statistics, the vulnerable road users are pedestrians in Latvia. The aim of this study is to investigate and analyse technical equipment used on non-signalled pedestrian crossings (zebra crossings) in Latvia and to make suggestions for measures that would increase road traffic safety on zebra crossings. RTAs involving collisions with pedestrians were filtered from the Ministry of the Interior database for a three-year period from 2016 to 2018. Thirty-two zebra crossings with a higher number of accidents with pedestrians were observed on the spot during the daylight and at night in several cities of Latvia. The main emphasis during the observation was placed on traffic signs and zebra road marking performance. Pedestrian crossings were observed from car driver's view by taking photographs during day-time and night-time observations. Most attention was paid to road sign and road marking visibility from driver's seat position. Retroreflection coefficient
\end{abstract}

* Corresponding author. E-mail:mseflers@mmm.com 
$\mathrm{R}^{\prime}$ was measured for each pedestrian crossing road sign. It was found that the condition and performance of traffic organisation equipment were not maintained on a regular basis and the life cycle of some traffic signs had well expired. Many road signs do not comply with minimum requirements, and road markings have weak visibility during wet weather conditions. It is recommended to improve visibility of pedestrian crossings from driver's view in the urban areas by increasing rain vision for road markings and higher retroreflection class for traffic signs.

Keywords: Pedestrian crossing, road marking, sign retroreflection, traffic accidents, traffic safety, traffic signs.

\section{Introduction}

Traffic safety is a major concern for every road user and especially for the vulnerable road users. Road safety depends on three basic factors: road user behaviour, vehicle performance and technical condition and the road infrastructure (Elvik et al., 2009). The Latvian statistics (CSDD, 2021) reveals that the number of fatalities and injuries in Latvia per million population is still consistently high. According to the road traffic accident statistics of the European Road Safety Council (ETSC, 2019), for several years Latvia has been occupying one of the last places among the European Union countries. The ratio of 69 deaths per million inhabitants is well above the average number of the EU Member States (i.e., 51 fatalities per million). The statistics show that the target set by the European Commission (EC, 2010) to reduce the number of road deaths by $50 \%$ compared to 2010 is not reached in Latvia. The European Commission set as its primary goal the prevention of human deaths in road traffic accidents (EC, 2021), which is linked to Vision Zero policy (Kristianssen et al., 2018) developed in Sweden since the 1990s.

According to the database of the Ministry of the Interior of Latvia (MOI, 2020), the vulnerable road users (pedestrians, bicyclists, quadracyclists, motorcyclists and riders of standing electrical scooters) formed half or $49.6 \%$ of the road deaths. From the total number of fatalities in Latvia in 2020 (139 road deaths), 43 fatalities (30.9\%) were pedestrians. In 25 cases, or $58 \%$ of the pedestrian fatalities have taken place during the dark hours. From 2010 to 2020, in total 43 fatalities occurred on non-signalled pedestrian crossings, 28 of them in dark hours, while in 22 cases the pedestrian crossings had some lighting. Due to the high proportion of vulnerable road users in the road deaths in Latvia and because of unsafe pedestrian crossings, this study analyses design and the condition of technical equipment on non-signalled pedestrian zebra crossings.
Equipment Condition for Zebra Crossing Night-Time Safety Performance in Latvia 
The goal of this study is to investigate and analyse technical equipment used on zebra crossings in Latvia and to make suggestions for measures that could increase road traffic safety. The main focus of this study is to evaluate whether the traffic management equipment when approaching zebra crossings is visible enough from driver's seat position during the day and at night.

Assessing the night-time performance, traffic sign retroreflection and zebra marking visibility from driver's seat position were observed and recorded. In the process of the study, the most unsafe non-signalled pedestrian crossings in Latvia were identified, where RTAs happened repeatedly. Then the zebra crossing equipment used on these crosswalks in several Latvian cities was observed and its condition was checked. The compliance of these solutions to the requirements set by the Latvian State Standards (hereinafter - LSS) was checked, and possible causes of repeated road accidents on these pedestrian crossings were evaluated. The minimum requirement by the LSS (LVS 190-10, 2007) to design non-signalled crossings is to have road signs No. 535 and 536 (pedestrian crossing) and road marking No. 931 (zebra) while the traffic rules require to give way to pedestrians on the crossing if either road marking or corresponding road signs are present (Road Traffic Regulations, 2015). It was also examined what kind of infrastructure and traffic management solutions for pedestrian crossings are used in other countries of the Baltic Sea Region and European Union on the nonsignalled pedestrian crossings.

There are various approaches in different countries how to manage traffic on non-signalled pedestrian crossings. Speed reduction by using speed humps can play significant influence on a potential collision severity level (Gitelman et al., 2017). Effective illumination infrastructure planning next to the pedestrian crossing helps reduce accidents with pedestrians during dark hours (Baleja, 2017). Type and condition of vehicle head lamps affect the visibility of road infrastructure during the night time. Performance of vehicle headlamps have been changed during the past decades. Modern LED headlamps are more focused on the road compared to Tungsten-Halogen lamps (Flannagan, 2019). Zebra road markings on pedestrian crossings play an essential role in drivers' and pedestrians' behaviour. On pedestrian crossings without road marking, driving speeds of vehicles increase and at the same time also the average waiting time when car stops increases for pedestrians (Gitelman et al., 2017). In Switzerland, through the pedestrian crossing road marking retroreflection and colour chromaticity tests, the authorities concluded to upgrade zebra marking performance in the national standard (Burghardt, Pashkevich, \& Mosbock, 2019). There are three retroreflection classes in use in 
European countries, where engineer grade films are defined as the lowest RA1 class, high intensity films - as class RA2 and diamond grade is the highest class RA3 (3M, 2018).

Several types of the retroreflective elements are used in sign sheeting production. Classic glass bead elements return back to driver up to $14 \%$ of light from a traffic sign. Modern high-performance microprismatic elements return back up to $58 \%$ of light and have better angularity, which is essential for heavy vehicle drivers, because their seating position is much higher compared to car drivers.

In a recent study (Brimley et al., 2017) on the safety benefits of upgrading to higher performance sign sheeting, the potential impact of improved night-time visibility of traffic signs could be substantiated. The City of Albuquerque, New Mexico, has upgraded its traffic signs in several segments of the city. The upgrade process replaced all traffic signs with signs made from the newest and highest performance materials. The analyses of this study compared the crash frequencies experienced on segments that had the upgraded signs with crash frequencies from years before the treatment on those segments or on segments in other parts of the city that had not yet been treated. Findings indicated that the upgraded signs might have contributed to reducing as many as 13 night-time crashes or 35\% across the entire collection of the treated segments.

\section{Research Methods}

\subsection{Road traffic accident data acquisition}

Road traffic accident database (MOI, 2020) was used to filter out repeating accidents with fatalities and injuries, involving pedestrians, from 2016 to 2018 (Fig. 1).

After detailed investigation of downloaded RTA data and checking them in the Google Street View (Sreet View, 2020), it was decided to inspect 32 non-signalled pedestrian crossing sites located between intersections on 2 and 4 driving line streets in different cities of Latvia, i.e., 19 crossings in Riga, 4 in Liepaja, 3 in Jurmala, 2 in Salaspils and single crossings in Bauska, Daugavpils and Sigulda. All pedestrian crossings were numbered from 1 to 32 in alphabetical order by their address. Observations of these crossings were done during 5 months in 2019, between August and December. The distinction between daylight and night time of RTAs occurred on the selected pedestrian crossings was done using dayandtime.com (TimeAndDate, 2019).
Equipment Condition for Zebra Crossing Night-Time Safety Performance in Latvia 


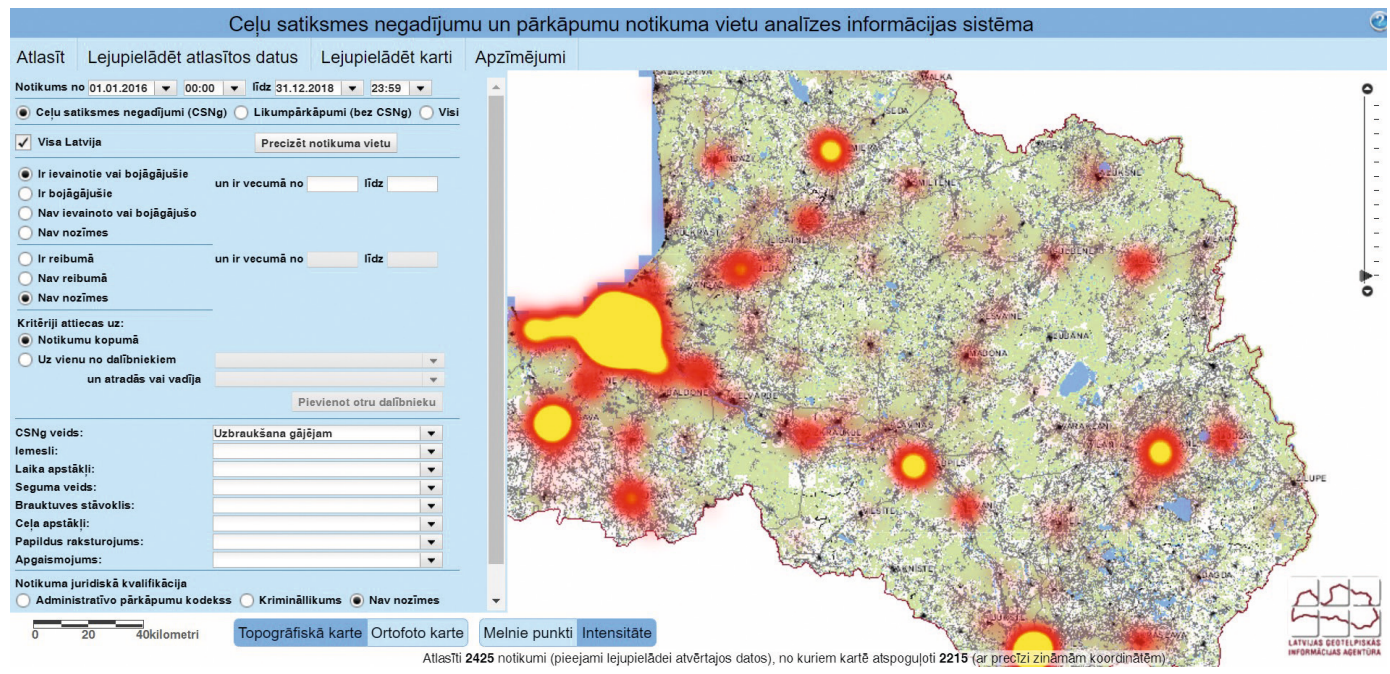

Figure 1. Pedestrian collision intensity map 2016 - 2018

\subsection{Observation methods of non-signalled pedestrian crossings}

Driver's view at the selected crossings during the daylight was observed from VW Passat B8 car and photo shots were taken from a longer distance around 30 meters and a closer distance of 10 to 15 meters (Fig. 2a and 2b) using photo camera Canon EOS M100, BK M15-45 S.

Observation of pedestrian crossings during night time was done from a car equipped with modern LED headlamps. Repeated observation tour for 13 crossings in the city of Riga was done at night with the

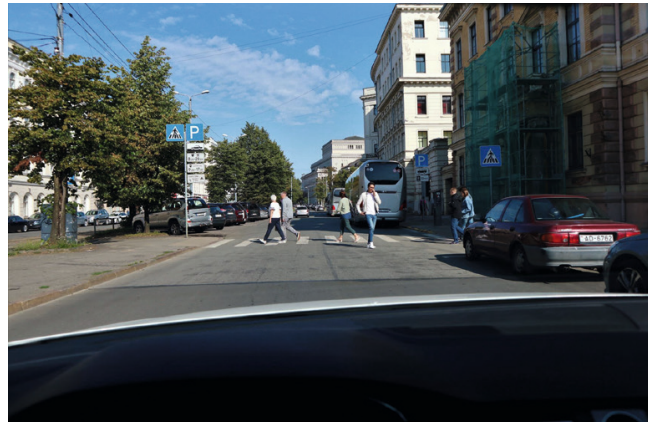

Figure 2a. Driver's view during daytime

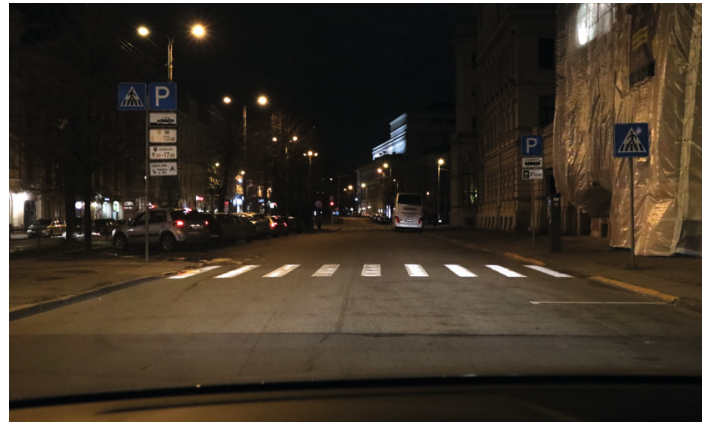

Figure 2b. Driver's view at night 
same car model but equipped with standard halogen type headlamps. It was determined whether additional solutions were used in order to attract driver's attention besides the minimal necessary equipment of pedestrian crossing signs and zebra road stripes defined in regulatory LSS (LVS 190-10, 2007). Date and weather conditions during the pedestrian crossing observations were fixed in the file as well. It was noted whether any other circumstances could influence driver's view to the crossing and recognising pedestrians in time.

\subsection{Methods of analysis of traffic management technical equipment}

Detailed information was collected about the pedestrian crossing signs on the selected crossings: age of the sign, condition, retroreflection class and reflective sheeting type (glass beaded or micro-prismatic) used in sign manufacturing. Measurements of retroreflection coefficient of pedestrian crossing signs No. 535 and No. 536 by Latvia road traffic rules were made by a handheld measuring instrument Delta RetroSign (Fig. 3). The data obtained were compared with regulatory standard (EN 12899-1:2007 Fixed vertical road traffic signs - Part 1: Fixed signs, 2007) tables of minimum requirements for retroreflection coefficient $R^{\prime}$ (cd lux ${ }^{-1} \mathrm{~m}^{-2}$ ) at observation angle $\alpha=20^{\prime}$ and entrance angle $\beta=+5^{\circ}$.

The average coefficient of retroreflection $R^{\prime}$ for each colour of signs from the collected data was calculated using Eqs. (1), (2) and (3).

where

$$
\begin{gathered}
R_{\mathrm{avd}}^{\prime}=\frac{\left(m_{1}+m_{2}\right)}{2}, \\
R_{\mathrm{avc}}^{\prime}=\frac{\left(m_{3}+m_{4}\right)}{2}, \\
R_{\mathrm{av}}^{\prime}=\frac{\left(R_{\mathrm{avd}}^{\prime}+R_{\mathrm{avc}}^{\prime}\right)}{2},
\end{gathered}
$$

$R_{\text {avd }}^{\prime}$ - average retroreflection of dirty sign;

$R_{\text {avd }}^{\prime}$ - average retroreflection of cleaned sign;

$m_{1}, m_{2}, m_{3}, m_{4}-$ measurement numbers;

$R_{\mathrm{av}}^{\prime}$ - average retroreflection of sign.

In cooperation with the Municipality Traffic Department, retroreflection coefficients $Q_{\mathrm{d}}$ and $R_{\mathrm{L}}$ were measured for zebra road marking lines on four pedestrian crossings in Liepaja. Measurements of three points on each zebra line were made using ZEHNTNER ZRM 6006 instrument. The results were compared with the minimum requirements of regulatory standard (BS Standards, 2018). The average coefficients of retroreflection and luminance for
Equipment Condition for Zebra Crossing Night-Time Safety Performance in Latvia 


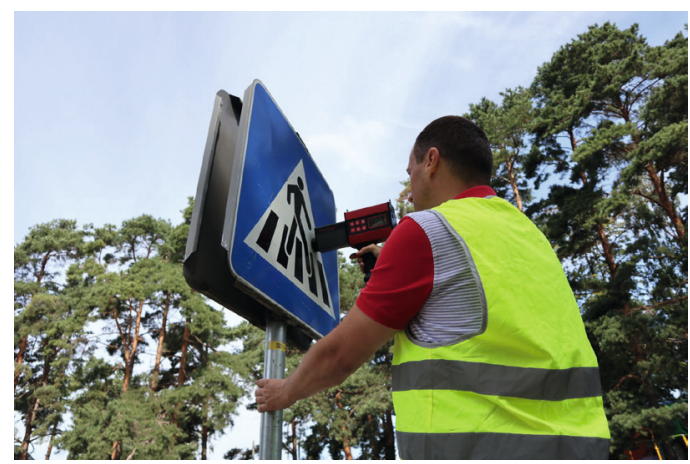

Figure 3. Measuring the road sign retroreflection

pedestrian crossing zebra marking lines were calculated from three measurements.

The photographs (see samples in Fig. 4a and Fig. 4b) taken during the night-time observations were uploaded into 3M Visual Attention Software (3M Visual Attention Software, 2020) to obtain information on which areas human eyes were tracking most when approaching the pedestrian crossing by a car and to detect if there were any circumstances in the infrastructure which could affect visibility of the pedestrian crossing. The option of outdoor/distant view was chosen for the analysis of the photographs in 3M VAS software. The general purpose of this software is not to assess road infrastructure but to analyse human eye attention to the outdoor advertisings within first 3-5 seconds. For this study, 3M VAS worked as a helping tool to identify potential factors to distract drivers' attention in order to timely recognise non-signalled pedestrian crossings. Yellow to red areas are most likely to draw immediate attention, but blue and green areas are less likely to draw immediate attention (Fig. 4a). Red regions evaluated

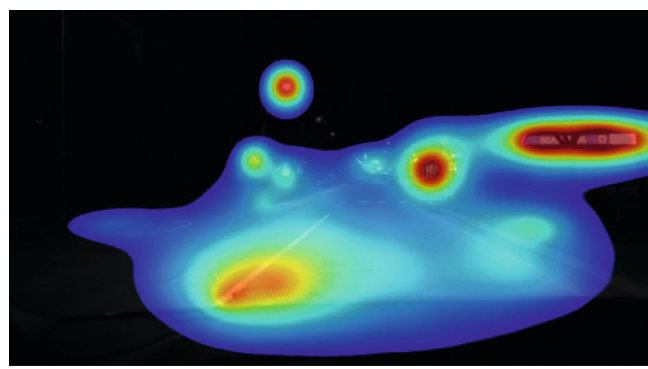

Figure 4a. 3M VAS heatmap analysis

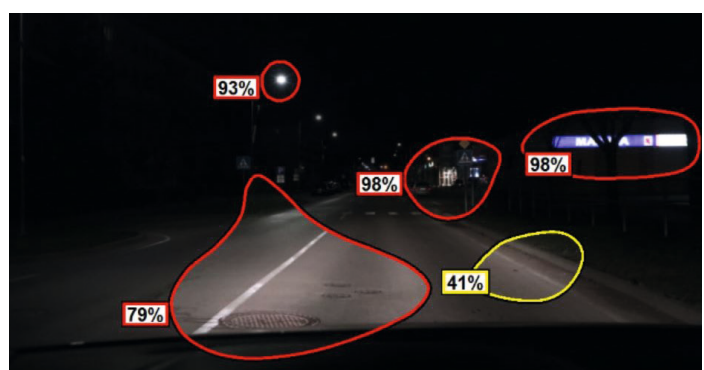

Figure 4b. 3M VAS region analysis 
by $70-99 \%$ intensity mean high probability and blue to green regions with 20-69\% intensity mean medium probability of human eye tracking (Fig. 4b).
Equipment Condition for Zebra Crossing Night-Time Safety Performance in Latvia

\section{Results}

In total, during the three-year period observed 2425 road accidents happened involving collisions with pedestrians (MOI, 2020). 85 collisions with pedestrians happened on the selected pedestrian crossings, 28 (32.9\%) of them happened during the dark hours. Majority of the selected RTAs occurred in Riga - 58 (68.2\%) and 18 (31.0\%) of them during the darkness. The daytime-night-time ratio in RTAs statistics in the capital of Latvia and in the other cities is similar. The usage of traffic management equipment on the observed non-signalled pedestrian crossings is shown in Table 1, the most dangerous crossings having four or more accidents are marked in bold.

Table 1. RTAs Statistics and Traffic Management Solutions Used on Pedestrian Crossings

\begin{tabular}{|c|c|c|c|c|c|c|c|c|c|}
\hline \multirow[b]{2}{*}{ Zebra crossing } & \multicolumn{2}{|c|}{ RTAs } & \multirow{2}{*}{ 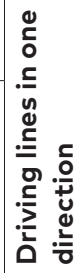 } & \multicolumn{3}{|c|}{ Traffic signs } & \multirow{2}{*}{ 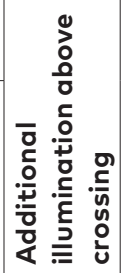 } & \multirow[b]{2}{*}{ 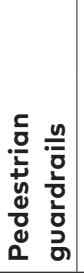 } & \multirow[b]{2}{*}{ Other solutions } \\
\hline & $\begin{array}{l}\bar{\delta} \\
\stackrel{0}{\circ} \\
\stackrel{-}{0}\end{array}$ & 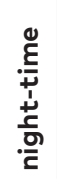 & & 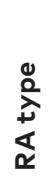 & 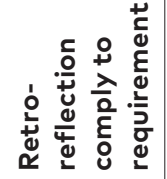 & 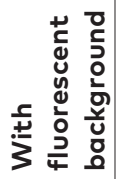 & & & \\
\hline \multicolumn{10}{|c|}{ Riga } \\
\hline Jurmalas Alley 87 & 6 & 1 & 1 & 1 & & & . & . & \\
\hline Kurzemes Avenue 58 & 5 & 2 & 2 & 1 & & & - & & $\begin{array}{l}\text { Speed control } \\
\text { camera }\end{array}$ \\
\hline Lacplesa Str 119 & 5 & & 2 & 3 & - & & - & & \\
\hline Kurzemes Avenue 23 & 4 & 1 & 2 & 1 & & & $\cdot$ & & \\
\hline Kalnciema Str 47 & 4 & 1 & 2 & 1 & & & - & & $\begin{array}{l}\text { Speed control } \\
\text { and additional } \\
\text { warning sign }\end{array}$ \\
\hline leriku Str 3 & 4 & 1 & 1 & 2 & - & & - & - & \\
\hline Aspazijas Boulevard 7 & 3 & 2 & 2 & 2 & - & & & & \\
\hline Kurzemes Avenue 124 & 3 & 1 & 2 & 1 & & & & & \\
\hline Lubanas Str 39B & 3 & 1 & 1 & 2 & & & - & - & \\
\hline Valdeku Str 15 & 3 & 1 & 1 & 1 & & & & & \\
\hline Graudu Str 6 & 2 & 1 & 1 & 2 & - & - & & & \\
\hline Valdeku Str 65 & 2 & 1 & 1 & 2 & - & . & - & . & \\
\hline
\end{tabular}




\begin{tabular}{|c|c|c|c|c|c|c|c|c|c|}
\hline \multirow[b]{2}{*}{ Zebra crossing } & \multicolumn{2}{|c|}{ RTAs } & \multirow{2}{*}{ 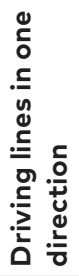 } & \multicolumn{3}{|c|}{ Traffic signs } & \multirow{2}{*}{ 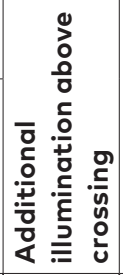 } & \multirow[b]{2}{*}{ 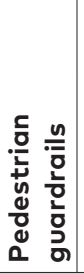 } & \multirow[b]{2}{*}{ Other solutions } \\
\hline & $\begin{array}{l}\overline{0} \\
\stackrel{0}{0}\end{array}$ & 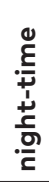 & & 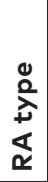 & 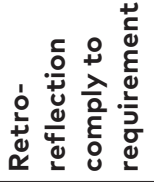 & 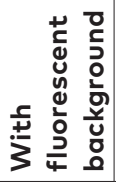 & & & \\
\hline Azenes Str 5 & 2 & & 1 & 1 & - & & & & Speed hump \\
\hline Marupes Str 25 & 2 & 1 & 1 & 1 & - & & & & \\
\hline Tallinas Str 69 & 2 & & 1 & 2 & - & & & - & \\
\hline K.UImana Alley 2 & 2 & & 2 & 2 & - & & - & - & \\
\hline Tilta Str 6 & 2 & 2 & 1 & 1 & & & & & \\
\hline Daugavgrivas Str 77 & 2 & 1 & 1 & 2 & • & - & • & & \\
\hline Juglas Str 2 & 2 & 1 & 1 & 1 & $\cdot$ & & & & \\
\hline \multicolumn{10}{|c|}{ Other cities } \\
\hline $\begin{array}{l}\text { Jurmala, J. Plieksana and } \\
\text { Lienes Str intersection }\end{array}$ & 5 & 4 & 2 & 2 & & • & - & & \\
\hline $\begin{array}{l}\text { Daugavpils, 18. Novembra } \\
\text { Str 66A }\end{array}$ & 3 & & 1 & 1 & • & & • & & \\
\hline Salaspils, Rigas Str 2 & 3 & 1 & 1 & 1 & & & - & & Overhead signs \\
\hline $\begin{array}{l}\text { Liepaja, Oskara Kalpaka } \\
\text { Str } 72 / 99\end{array}$ & 2 & 1 & 1 & 1 & & • & & & \\
\hline Liepaja, Liela Str 13 & 2 & & 1 & 1 & • & & & & \\
\hline $\begin{array}{l}\text { Jurmala, Maza Nometnu } \\
\text { and Tallinas Str } \\
\text { intersection }\end{array}$ & 2 & 1 & 1 & 1 & & & & & \\
\hline Bauska, Pionieru Str 1 & 2 & & 1 & 1 & - & & & & \\
\hline Salaspils, Skolas Str 5 & 2 & 1 & 1 & 1 & & & & • & \\
\hline $\begin{array}{l}\text { Liepaja, Oskara Kalpaka } \\
\text { Str } 109\end{array}$ & 1 & & 1 & 2 & $\bullet$ & - & & & \\
\hline Jelgava, Pasta Str 51 & 1 & & 3 & 1 & - & & & & \\
\hline Liepaja, Liela Str 11 & 1 & & 1 & 1 & $\cdot$ & & - & & \\
\hline $\begin{array}{l}\text { Jurmala, Maza Nometnu } \\
\text { Str 112B }\end{array}$ & 1 & 1 & 1 & 1 & & & & • & \\
\hline Sigulda, Ausekla Str 6 & 2 & 1 & 1 & 1 & & & & & \\
\hline Total: & 85 & 28 & & & 17 & 6 & 14 & 8 & \\
\hline
\end{tabular}

For the purpose of this paper, the seven zebra crossings where four or more RTAs happened in the time period investigated were classified as the most dangerous zebra crossings. It can be noticed that among the selected zebra crossings having most collisions involving pedestrians only one is equipped with speed hump being an effective speed reduction solution and only two are in the range of speed camera, while 


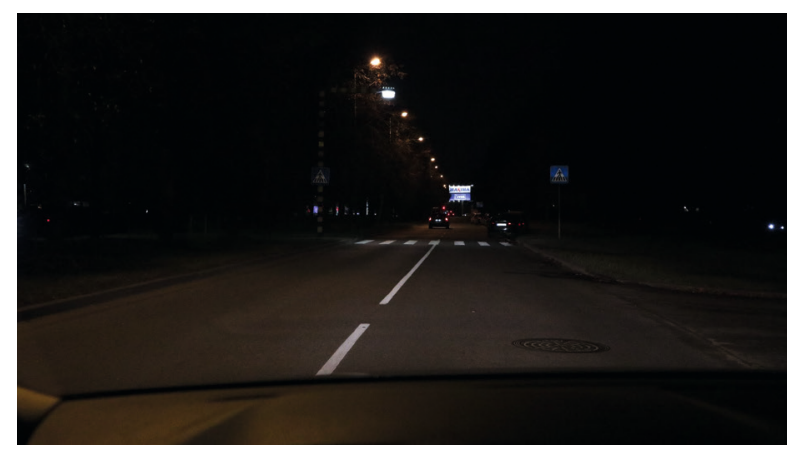

Figure 5. Pedestrian crossing with additional illumination.

Driver's view at night

several other crossing safety enhancement solutions are more widely represented. The most popular additional equipment is illumination above the pedestrian crossing (Fig. 5). It is installed on 14 out of 32 pedestrian crossings observed. 13 of the total 28 RTAs during the night-time occurred on the crossings with additional illumination. This means that the division between RTAs on illuminated and nonilluminated pedestrian crossings is very similar; 13 and 15 collisions with pedestrians during the dark hours of the day. In order to attract the attention of drivers during the daytime, some illumination poles are mounted with contrasting painting metal plates.

The most commonly recognised problematic issue on the illuminated pedestrian crossings is the ground cover by the illumination or the light cone. Quite often it illuminates just the carriageway and there is a lack of light in the areas where pedestrians approach crossing. Due to this reason, the risk of non-noticing the pedestrians increases essentially.

Different approaches how to maintain pedestrian crossing marking lines in Latvia were recognised during the observation. Most commonly used road marking types on the observed pedestrian crossings are cold or thermo-plastic materials. For certain cases, paint materials were also documented. During the daytime observations, in general, zebra markings performed well and were visible good enough from the driver's view perspective. During the night-time observations, the issues with visibility popped out in wet conditions which in Latvia are very common from autumn until the early spring, September to April.

Road marking retroreflection coefficient measurement results from the investigation in Liepaja on pedestrian crossings (PC) 7 to 10 show different results for different types of road marking materials (Fig. 6).
Equipment Condition for Zebra Crossing Night-Time Safety Performance in Latvia 


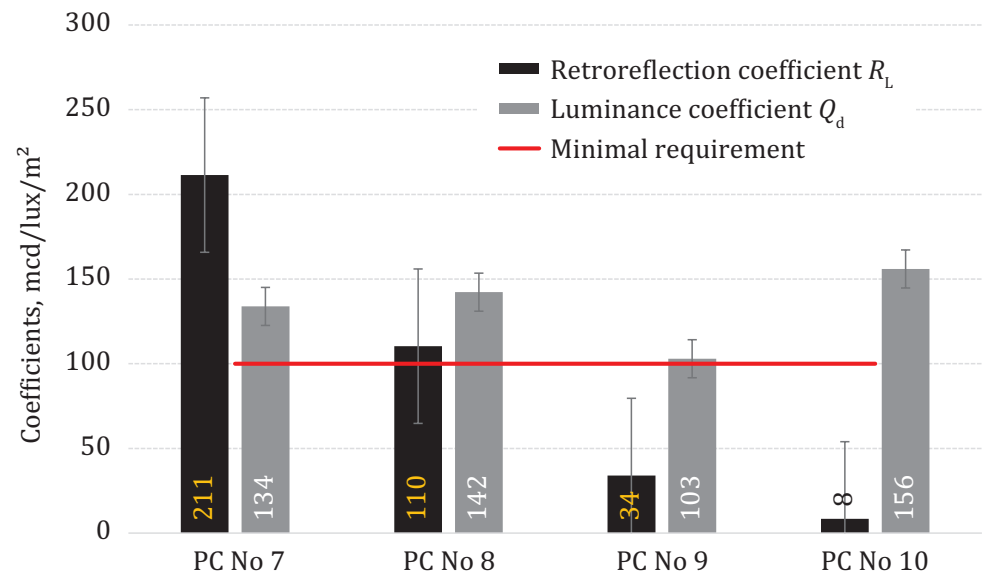

Figure 6. Average retroreflection luminance coefficients per crossing in Liepaja

On all crossings measured, the luminance coefficient under diffuse illumination $Q_{\mathrm{d}}$ was within the standard norms. At the same time, nonconformity was recognised for retroreflection coefficient $R_{\mathrm{L}}$ on two pedestrian crossings where paint marking type was in use. On crossing No. 9 (O. Kalpaka Str, Liepaja) the average retroreflection coefficient $R_{\mathrm{L}}$ as $34 \mathrm{mcd} \mathrm{m}^{-2} \mathrm{lux}^{-1}$ only at minimum requirement $100 \mathrm{mcd} \mathrm{m}^{-2} \mathrm{lux}^{-1}$.

Due to the rainfall before the measurements on crossing No. 10 (0. Kalpaka str, Liepaja), the retroreflection coefficient obtained cannot be legally matched against the Latvian standard requirement because it does not set requirements for road markings under wetness. The average retroreflection values on the wet zebra markings were found at very low level of $8 \mathrm{mcd} \mathrm{m}^{-2} \mathrm{lux}^{-1}$.

By the regulation of road marking line width on pedestrian crossings (LVS 85:2016 Road markings, n. d.), it is allowed to use two types of line width in Latvia: $40 \mathrm{~cm}$ and $50 \mathrm{~cm}$. At the same time, none of 32 observed pedestrian crossings have $50 \mathrm{~cm}$ wide zebra lines.

Traffic signs No. 535 and No. 536 (pedestrian crossing) were inspected in detail for all observed crossings. There is no requirement to install pedestrian crossing signs from higher retroreflection class RA2 or RA3 in Latvia; therefore, the lowest performing type RA1 (Engineer grade reflective sheeting) is commonly used for traffic signs No. 535 and No. 536. The chart below (Fig. 7) shows all observed pedestrian crossing signs split by retroreflective class and sheeting type.

At the time of inspection, the average pedestrian crossing sign age was 11.4 years. The highest average age was found for class RA1 glass 


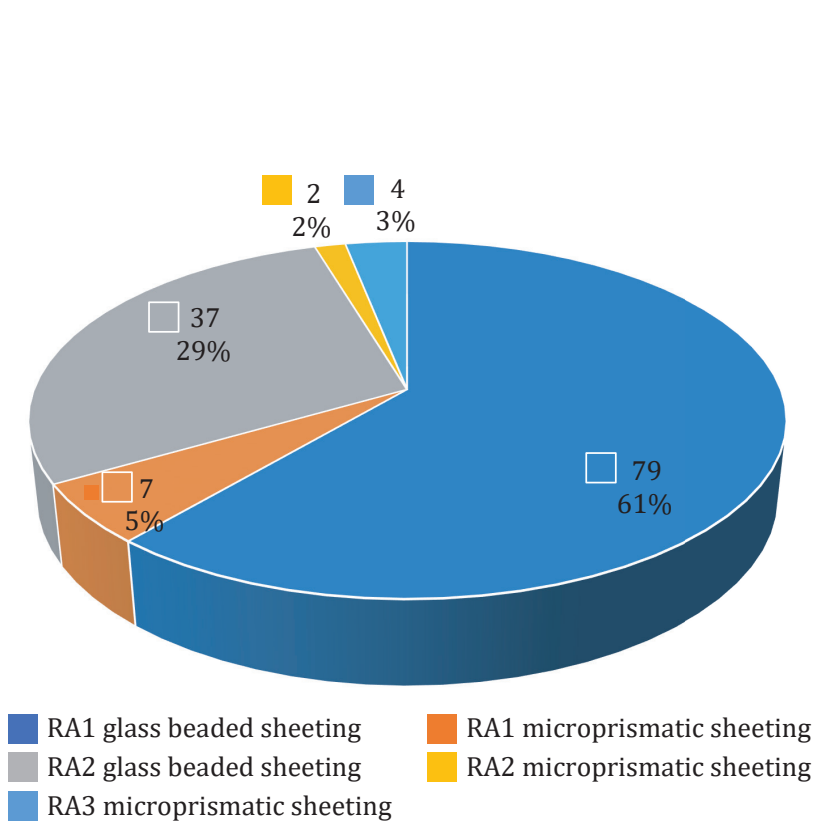

Maris Seflers,

Juris Kreicbergs,

Gernot Sauter

Equipment Condition

for Zebra Crossing

Night-Time Safety

Performance

in Latvia

Figure 7. Pedestrian crossing signs by RA class and sheeting type

beaded sheeting signs. At the time of inspection, it was close to 15 years. Six crossings had traffic signs with at least 20 years of age. The high performing type signs produced from micro-prismatic reflective sheeting class RA2 and RA3 were recognised on 2 pedestrian crossings only, both of them in Riga. Noteworthy that out of seven RTAs with pedestrians none happened on these two crossings during the dark hours.

59 pedestrian crossing signs or $45.7 \%$ of total inspected signs had cracks on the sign face. Surface cracking is a typical failure mode for the 'enclosed lens sheeting' construction that has been standardized in ASTM D4956 as 'Type I' and EN 12899-1 as 'Class RA1' and typically designated as 'Engineer Grade sheeting' (EG). Surface cracking is the visual indication that polymers have degraded and the sign is no longer functional. In that context, it is good to understand that the limited durability of enclosed lens sheeting is also reflected in the manufacturer warranty periods. While EG sheeting is only warranted for 7 years at $50 \%$ retroreflectivity retention, modern microprismatic sheetings are warranted for up to 12 years at a retained performance level of $80 \%$ retroflectivity. These facts are also documented in some regulations, e.g., the Austrian Law for Traffic Signs (StVZVO, 1998). Therefore, the expected night-time conspicuity and visibility of some pedestrian crossings with aged and low performance sign sheeting were found quite poor. Nevertheless, the old EG type beaded sheeting is still used in pretty high quantities in Latvia. When assessing the investigated crossings, 


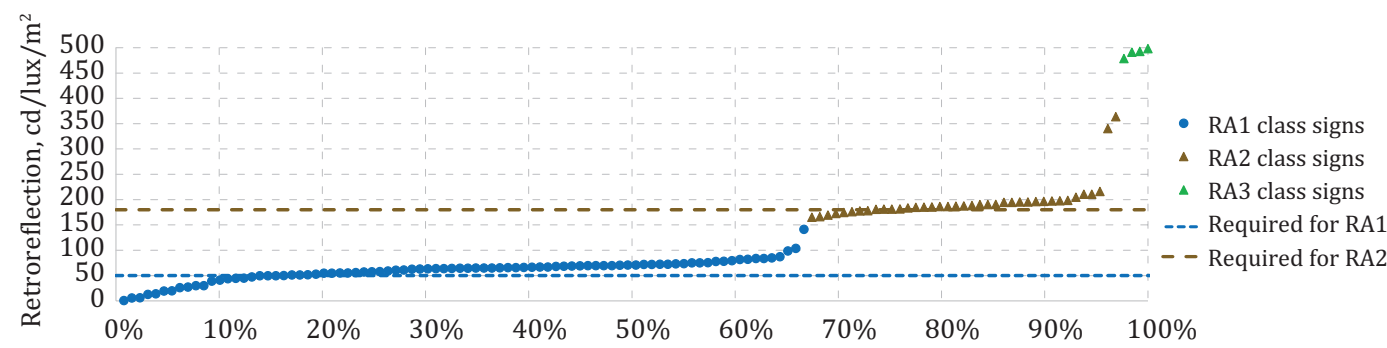

Share of traffic signs corresponding to the retroreflection coefficient value

Figure 8. Traffic sign retroreflection coefficient for the white colour

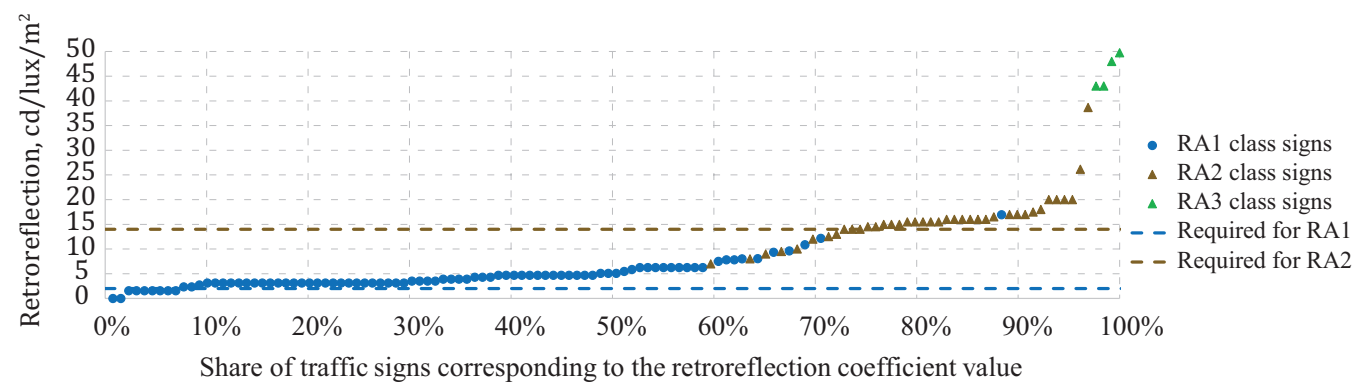

Figure 9. Traffic signs retroreflection coefficient for the blue colour

additionally the retroreflection coefficient conformity to existing standards was checked. Nonconformity to the minimum retroreflection coefficient required for the white colour was found on 29 signs $(22.5 \%$ of 129 signs observed) (Fig. 8) and for the blue colour on 17 (13.2\%) traffic signs (Fig. 9).

In Riga, on three pedestrian crossings, sign upgrade to higher retroreflection class was noticed in 2018, but these signs were manufactured from lower retroreflection performance glass bead sheeting RA2B and their coefficient of retroreflection already was on the edge of minimal requirement. Class RA2B does not exist in mandatory standard of Latvia (LVS 77-2, 2016); these signs might be not be compliant with the national traffic code.

The minimal requirements for pedestrian crossing sign retroreflection performance class were compared to other neighbouring countries and some countries with the highest road safety level in Europe. Figure 10 shows that Latvia is the only country from the ones compared where it is legal to install RA1 class (Engineer grade) traffic signs on the pedestrian crossings. 


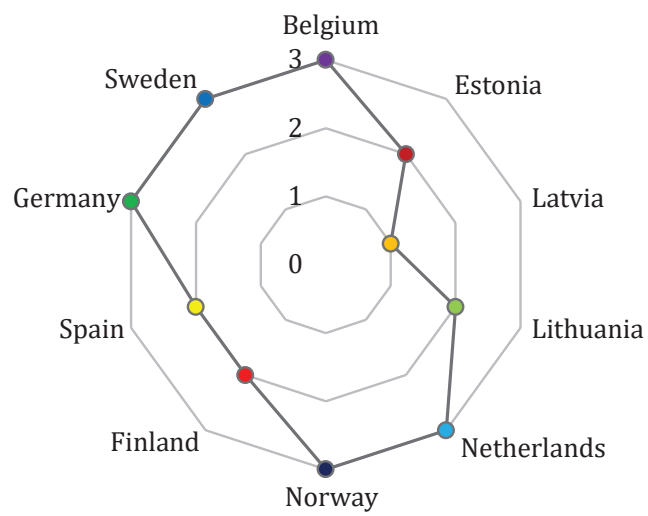

Figure 10. Comparison of pedestrian crossing sign RA class minimum requirement among countries

During the night-time observations, several infrastructure elements which could influence driver's ability to detect pedestrian crossings were recognised. Even if the crossings are noticed, they diminish the ability to notice pedestrians within a safe stopping distance. The street illumination and illuminated outdoor advertising are taking the most of human eye attention (Fig. 11).

Zebra crossing signs do not provide good enough illuminance in a particular infrastructure environment; traffic signs may be hardly noticeable to drivers. As shown in the 3M VAS analyser, most of the human eye attention goes to the illuminated advertisement of the shopping mall, software does not recognise zebra crossing signs and road marking stripes at all. Road markings do not provide retroreflection (Fig. 11) during rainy condition at night; therefore, they

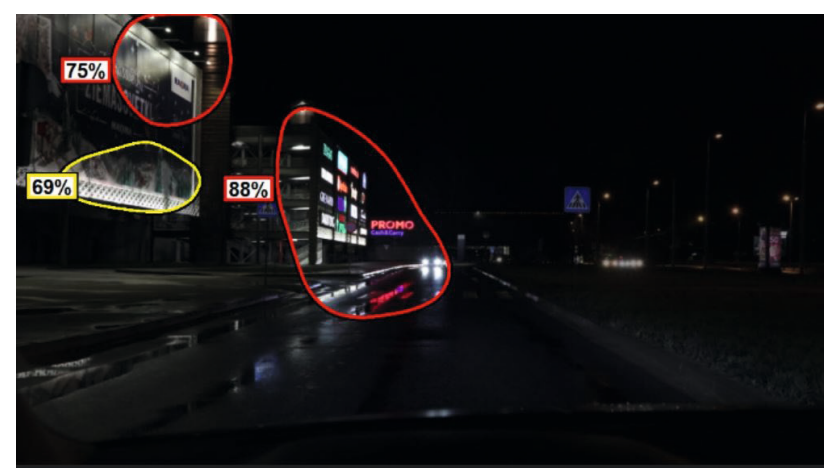

Figure 11. Driver's view at night by 3M VAS photography analyser
Equipment Condition for Zebra Crossing Night-Time Safety Performance in Latvia 


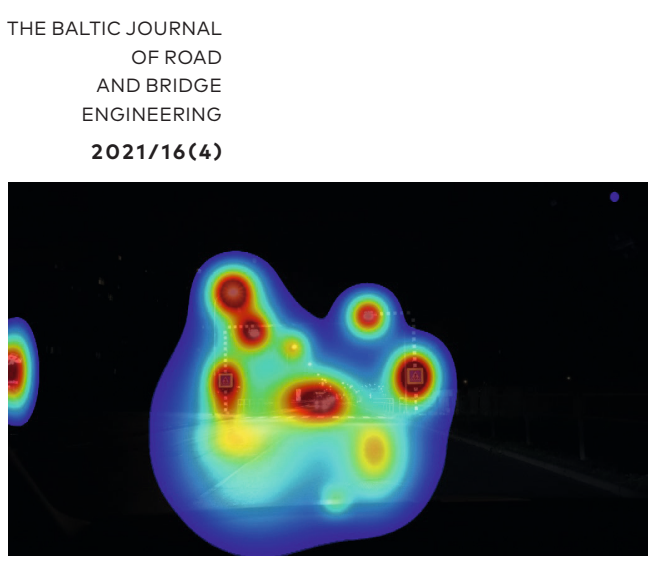

Figure 12a. 3M VAS heatmap analysis; LED lamps

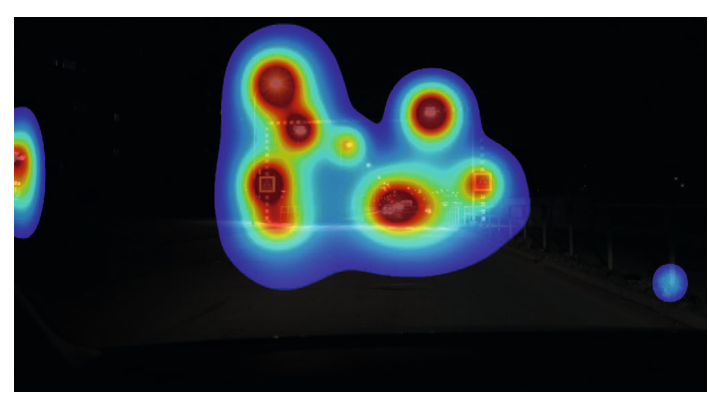

Figure 12b. 3M VAS heatmap analysis; Halogen lamps

are not visible in the photography from the driver's seat position. 3M VAS analysis was performed with all zebra crossing photographs taken during the night-time observation.

It was not clear if the software gave different results to LED headlamps and Tungsten-Halogen lamps. That was the main reason why night-time observation from car was done twice - with the same car model (VW Passat B8) but different headlamp types. Photographs were analysed in 3M Visual Attention Software (3M Visual Attention Software, 2020). Outcomes from 3M VAS show (Fig. 12a and Fig. 12b) that classic Halogen lamp light cone is more scattered and traffic signs are more illuminated, but LED light beam provides more focus on road, while the analysis software in both cases showed the same spots to be attracted by the human eye.

\section{Conclusions}

Various technical solutions and equipment condition were analysed for Zebra pedestrian crossings where several traffic accidents involving pedestrian injuries happened in municipalities of Latvia. The most dangerous non-signalled pedestrian crossings were found in Riga and Jurmala with 33 accidents on seven pedestrian crossings. Five of these pedestrian crossings are on road sections with four driving lines. Old and low performing traffic signs were observed on five crossings. One pedestrian crossing on Jurmala Avenue in Riga was found too close to a bus stop. Potential influence to detect non-signalled crossings from distance due to street illumination and illuminated advertisement was recognised in the area of all seven crossings. General observations confirm that most of the non-signalled pedestrian zebra crossings may be unnoticeable for car drivers. Night-time collision statistics does not show significant difference 
between the illuminated pedestrian crossings and the crossings without additional illumination. It was found that the technical equipment on the investigated pedestrian crossings was not properly maintained and timely replaced. Many traffic signs have defects like cracking of sign faces and non-compliance with the minimal requirements of retroreflection stated by the Latvian and European standards. Only one observed pedestrian crossing is equipped with high performing reflective class 3 signs. The sign was very easy to notice from the driver's view on the illuminated advertising background during the nigh-time observation. The most common shortcomings of the examined high risk pedestrian crossings were weakly visible traffic signs during the night-time, non-reflective pavement zebra marking lines during wet road conditions and distractions like illuminated advertising, street illumination and bus stops next to the pedestrian crossings. No traffic calming solutions in order to reduce vehicle speed when approaching the non-signalled pedestrian crossings were used on the examined crossings with high accident records except for fixed speed control cameras at two crossings in Riga.

In order to increase traffic safety on the non-signalled pedestrian crossings in Latvia, it is worth starting with efficient low-cost solutions. It is recommended to improve visibility of pedestrian crossings from the driver's view by increasing the performance levels of pedestrian crossing equipment, such as wet reflective pavement markings and higher retroreflection classes for traffic signs. The respective requirements in Latvian standards should be raised to internationally recommended levels. A technically easy improvement is to implement traffic sign upgrade program from RA1 class beaded sheeting to RA3 class pedestrian crossing signs.

The second recommendation can be made for the width of the zebra marking. The existing regulation in Latvia allows both $40 \mathrm{~cm}$ and $50 \mathrm{~cm}$ width. However, none of the 32 observed crossings were marked with $50 \mathrm{~cm}$ lines. It can be stated that a general rule for $50 \mathrm{~cm}$ wide markings would improve night-time visibility. Another cost-effective solution is allweather visible road markings. ERF recommendations (ERF, European Union Road Federation, 2018) for the minimum requirement on road markings in use are $150 \mathrm{mcd} \mathrm{lux}^{-1} \mathrm{~m}^{-2}$ in dry weather conditions and 35 mcd lux $^{-1} \mathrm{~m}^{-2}$ in wet and rainy conditions.

During the night-time observation and analysis with the Visual Attention Software, there were several locations where street illumination and illuminated outdoor advertising took most of the human eye attention. Driver's attention is distracted, and drivers are not able to see pedestrians within a safe distance. It is recommended to put more emphasis on the surrounding conditions, in which pedestrian crossings are placed.
Equipment Condition for Zebra Crossing Night-Time Safety Performance in Latvia 


\section{Acknowledgements}

The authors would like to thank 3M Transportation Safety Division for supporting this study and providing a tool for measuring retroreflection coefficient of traffic signs on crosswalks. The authors express their gratitude to Liepaja Municipality Traffic Department Office "Komunala parvalde" for supporting with a road marking retroreflection measuring tool and active participation in the inspection of crosswalks in the city of Liepaja.

\section{REFERENCES}

3M. (2018). 3M Science. Applied to Life. Retrieved from Driving Road Safety in the Right Direction: https://multimedia.3m.com/mws/media/15349600/traffic-signage-brochure-2018-pdf.pdf

3M Visual Attention Software. (2020). Retrieved from https://www.3m. com/3M/en_US/visual-attention-software-us/

Baleja, R. (2017). Increasing of visibility on the pedestrian crossing by the additional lighting systems. IOP Conference Series: Materials Science and Engineering, 236, 012099. https://doi.org/10.1088/1757899X/236/1/012099

Brimley, B. K., Mousavi, S. M., Carlson, P., \& Dixon, K. K. (2017). Safety effects of traffic sign upgrades in Albuquerkque, New Mexico. Retrieved from https:// www.researchgate.net/publication/331950531_Safety_Effects_of_Traffic _ Sign_Upgrades_in_Albuquerque_New_Mexico

Burghardt, T. E., Pashkevich, A., \& Mosbock, H. (2019). Yellow pedestrian crossings: from innovative technology for glass beads to a new retroreflectivity regulation. Retrieved from https://www.sciencedirect. com/science/article/pii/S2213624X1930077X

CEN. (2018). EN 1436 Standard. Retrieved from https://www.en-standard. eu/bs-en-1436-2018-road-marking-materials-road-marking-performance-for-road-users-and-test-methods/?gclid=EAIaIQobChMI-f-79Pic6gIViU8YCh3FeQYrEAMYASAAEgJjXfD_BwE

CSDD. (2021). The Road Traffic Safety statistics. Retrieved from CSDD: https:// www.csdd.lv/en/road-accidents/the-road-traffic-safety-statistics

EC. (2010). European Commission. Retrieved from https://ec.europa.eu/ transport/road_safety/sites/roadsafety/files/pdf/com_20072010_en.pdf

EC. (2021). European Commission. Mobility and Transport. Retrieved from Road Safety2021: https://ec.europa.eu/transport/road_safety/what-we-do_en

Elvik, R., Hoye, A., Vaa, T., \& Sorensen, M. (2009). The Handbook of Road Safety Measures. Bingley: Emerald Group publishing Limited. https://doi.org/10.1108/9781848552517

EN 12899-1:2007 Fixed vertical road traffic signs - Part 1: Fixed signs. (2007). Retrieved from https://www.en-standard.eu/din-en-12899-1-fixed-verticalroad-traffic-signs-part-1-fixed-signs/ 
ERF, European Union Road Federation. (2015). Improved Signage for Better Roads. Retrieved from https://erf.be/publications/improved-signage-forbetter-roads/

ERF, European Union Road Federation. (2018). European Union Road Federation. Retrieved from https://erf.be/publications/marking-the-way-towards-asafer-future/

ETSC, European Transport Safety Council. (2019). European Transport Safety Council. Retrieved from https://etsc.eu/euroadsafetydata/

Flannagan, M. J. (2019). A market-weighted description of Tungsten-Halogen and LED low beam headlighting patterns in the US. Retrieved from https:// deepblue.lib.umich.edu/handle/2027.42/154777

Gitelman, V., Carmel, R., Pesahov, F., \& Chen, S. (2017). Changes in road-user behaviors following the installation of raised pedestrian crosswalks combined with preceding speed humps, on urban arterials. Transportation Research Part F: Traffic Psychology and Behaviour, 46(Part B), 356-372. https://doi.org/10.1016/j.trf.2016.07.007

Gitelman, V., Carmel, R., Pesahov, F., \& Hakkert, S. (2017). An examination of the influence of crosswalk marking removal on pedestrian safety as reflected in road user behaviours. Transportation Research Part F: Traffic Psychology and Behaviour, 46(Part B), 342-355. https://doi.org/10.1016/j.trf.2016.03.007

Kristianssen, A. C., Andersson, R., Belin, M. A., \& Nilsen, P. (2018). PW 1702 Swedish Vision Zero policies for safety - A comparative policy content analysis. Injury Prevention, 24(S2). https://doi.org/10.1136/injuryprevention-2018-safety.205

LVS 190-10. (2007). Rules for the design of pedestrian crossing. Retrieved from https://www.lvs.lv/lv/products/146441

LVS. (2016). Retrieved from LVS 77-2:2016: https://www.lvs.lv/lv/ products $/ 97917$

LVS 85:2016 Road markings. (n. d.). Retrieved from https://www.lvs.lv/lv/ products/97916

MOI. (2020). CSDD. Retrieved from http://gis.ic.iem.gov.lv/giswebcais/

Road Traffic Regulations. (2015, June 2). Retrieved from https://likumi.lv/ta/ id/274865-celu-satiksmes-noteikumi

Sreet View Map. (2020). Retrieved from https://www.google.com/maps/d/view er?msa=0\&ie=UTF8\&t=h\&ll=56.97929953432196\%2C 24.531518758820376 \&mid=1JEkfH9bJtMKrVCMHrKGPP_QmMys\&z=7

StVZVO. (1998). Retrieved from https://www.ris.bka.gv.at/Dokumente/ BgblPdf/1998_238_2/1998_238_2.pdf

TimeAndDate. (2019). timeanddate.com. Retrieved from https://www. timeanddate.com/astronomy/latvia
Equipment Condition for Zebra Crossing Night-Time Safety Performance in Latvia 